\title{
Perioperative Management of Cardiovascular Risk in Vascular Surgery Patients: What's New in 2014?
}

\author{
Jennifer B Cowart*, Jeffrey T Bates and Addison A Taylor
}

Michael E DeBakey VA Medical Center, Baylor College of Medicine, Houston, Texas, USA

*Corresponding author: Jennifer B Cowart, Michael E. DeBakey VA Medical Center, Baylor College of Medicine, Houston, Texas, USA, Tel: 713-794-7297; E-mail: Jennifer.cowart@va.gov

Rec date: Nov 19, 2014; Acc date: Nov 29, 2014; Pub date: Dec 1, 2014

Copyright: (C) 2014 Cowart JB, et al. This is an open-access article distributed under the terms of the Creative Commons Attribution License, which permits unrestricted use, distribution, and reproduction in any medium, provided the original author and source are credited.

\begin{abstract}
Preoperative Cardiovascular (CV) risk stratification and management of medical comorbidities have undergone major changes in the past two decades. Two new risk stratification tools have been developed and validated to complement the Revised Cardiac Risk Index (RCRI) originally implemented in 1999. Since these tools have not yet been compared, the most recent guidelines merely recommend that one of these validated tools be used when risk stratifying patients preoperatively. The most recent guidelines for perioperative medical management of patients undergoing non-cardiac surgery have placed less emphasis on use of beta-blockers and more emphasis on the potential benefits of HMG-CoA reductase inhibitors, or statins, as studies have emerged reporting reductions in perioperative atrial fibrillation, impairment of renal function and in the rate of growth of abdominal aortic aneurysms. The guidelines also emphasize the importance of antiplatelet therapy but do not comment on smoking cessation, interventions which are often underutilized. This review will focus on strategies for CV risk reduction in vascular surgery patients, both perioperatively and long term.
\end{abstract}

Keywords: Vascular surgery; Abdominal Aortic Aneurysm (AAA); Peripheral Arterial Disease (PAD); Statin; HMG-Co-A-reductase inhibitor; Atorvastatin; Simvastatin; Rosuvastatin; Coronary disease; Atherosclerotic Vascular Disease (ASCVD); Lipids; Lipid-lowering; EVAR; PEVAR; Beta-blocker; Metoprolol; Carvedilol; Nebivolol; Aspirin; Clopidogrel; Smoking cessation; Varenicline; Nicotine replacement therapy; Bupropion

\section{Introduction}

The past decade has seen significant changes in recommendations for perioperative cardiac risk stratification and management of medical co-morbidities for patients undergoing non-cardiac surgery, including vascular surgery [1-3]. Recently published American College of Cardiology/American Heart Association (ACC/AHA) guidelines for the perioperative evaluation and management of patients undergoing non-cardiac surgery reflect these changing paradigms and highlight the uncertainty about how, when and in whom we should be using cardiovascular (CV) therapies such as beta-blockers, statins, antiplatelet agents, and smoking cessation [4-6]. This review will discuss these changes, specifically as they apply to vascular surgery patients, and will highlight current practices based on evidence from clinical trials or on expert opinion when it is not. As less evidence is available to guide perioperative glucose control and blood pressure management in patients undergoing vascular surgery, these subjects will not be covered here.

\section{Preoperative Risk Guidelines}

In 2007, the ACC/AHA Guidelines for the perioperative management of patients undergoing non-cardiac surgery incorporated the Lee Revised Cardiac Risk Index (RCRI) to simplify the risk stratification of preoperative patients $[1,3,7]$. The RCRI includes five patient-specific factors (congestive heart failure, ischemic heart disease, chronic kidney disease, diabetes on insulin, and history of cerebrovascular disease) as well as the estimated CV risk of the planned surgical procedure. Based on the results of the RCRI risk stratification and the risk of the procedure, the 2007 guidelines recommended reserving preoperative invasive and non-invasive cardiac testing to only those high-risk patients in whom such testing would change perioperative management. These guidelines were updated in 2014 [4]. Two new risk stratification models have been added to the Lee RCRI. The American College of Surgeons National Surgery Quality Improvement Project (NSQIP) Myocardial Infarction or Cardiac Arrest (MICA) calculator was validated in a population of $>400,000$ patients and uses surgery-specific risk in addition to the American Society of Anesthesiologists (ASA) score and functional status to estimate postoperative myocardial infarction (MI) or cardiac arrest [8]. The American College of Surgeons NSQIP Surgical Risk Calculator uses more detailed procedural information by Current Procedural Terminology(CPT) code as well as risk factors such as steroid use, Body Mass Index (BMI), dialysis, etc., and produces risk estimates for a wide range of outcomes, including pneumonia, surgical site infection, Venous Thromboembolism (VTE), or death [9]. The 2014 ACC/AHA Perioperative Guideline recommends use of a "validated risk-prediction tool" without a specific recommendation for any of the three models. Cardiac testing remains reserved for those patients at highest risk of $\mathrm{CV}$ complications in whom testing would change management.

\section{Preoperative Beta-Blockers: Changes to the Guidelines}

Since the publication of the ACC/AHA guidelines in 2007, the greatest evolution in the perioperative medical management of patients undergoing non-cardiac surgery has been in the recommendations for the use of beta-blockers. The most notable changes have occurred for at least three reasons. First, these guidelines 
incorporated findings of the DECREASE trials for use of preoperative beta-blockers $[10,11]$. However, the results of these trials have been questioned due to findings of scientific misconduct through falsification and fabrication of data by the trials' senior investigator [12]. Second, publication of the POISE trial in 2008 complicated the previous recommendations. This trial randomized $>8000$ beta-blocker naïve patients undergoing non-cardiac surgery to receive $100 \mathrm{mg}$ metoprolol succinate or placebo 2-4 hours prior to surgery and $200 \mathrm{mg}$ daily for 30 days after surgery [13]. The POISE trial reported that more patients receiving metoprolol had hypotension and strokes but fewer patients had MIs post-operatively than those on placebo. Third, evidence from trials involving non-surgical patients with heart failure, recent acute MI, or who at high risk for cardiac events, suggested that not all beta-blockers share the same salutary effect on CV mortality and morbidity [14]. Thus, the guidelines for the perioperative use of beta-blockers were revised in 2009 [15], and again in 2014 [5]. The most current recommendations are based on a combination of evidence from clinical trials that exclude the DECREASE trials $[10,11]$ and, to a lesser extent, POISE [13], and include practical recommendations based on expert opinion when clinical trial evidence is lacking. These recommendations are summarized in Table 1.

\section{Statins in Perioperative Management}

Work in the past several years has illustrated the continued importance of perioperative risk stratification and management, especially in patients at high risk for cardiac events. Vascular surgery patients are at higher risk than the general population, likely due to the stressful nature of the surgeries they undergo in addition to the higher probability that they may have subclinical coronary disease. Recently published guidelines for the management of lipid disorders recommend that patients at high risk for $\mathrm{CV}$ events be treated with HMG-CoA-reductase inhibitors, or statins, regardless of their pretreatment LDL-cholesterol or non-HDL-cholesterol levels [6]. This recommendation applies to the vast majority of patients for whom vascular surgery is being contemplated.

\section{Preoperative statins may reduce perioperative adverse events}

A number of retrospective and observational studies suggest that statins may reduce multiple perioperative complications. Bhaveet al. reported reduced risk of perioperative atrial fibrillation in non-cardiac surgery patients [16]. Post-hoc analysis of the DREAM trial demonstrated that patients on statins prior to undergoing either open or endovascular abdominal aortic aneurysm (AAA) repair had improved survival and fewer $\mathrm{CV}$ deaths compared to patients not receiving statins [17]. An observational study of 328 patients with asymptomatic carotid stenosis undergoing elective Carotid Endarterectomy (CEA) showed that patients on statins had lower risk of clinical stroke and cognitive dysfunction post-operatively compared to those not on statins [18]. Statins have also been reported to ameliorate the immediate postoperative reduction in renal function following endovascular repair of AAA, but had no effect on the deterioration noted at 6 and 12 months in these patients [19]. The possible renal protection afforded by statins for other vascular procedures requires additional study. A retrospective study found that perioperative statin use in non-cardiac surgery was associated with decreased 30-day non-cardiac complications, including respiratory and infectious complications [20]. Finally, a retrospective analysis of all vascular surgery patients (including CEA/CAS, suprainguinal and infrainguinal bypass, open and endovascular AAA repair) demonstrated that patients on antiplatelet and statin medications preoperatively had decreased 30 -day mortality and $18 \%$ improvement in 5-year survival [21]. This analysis also demonstrated that at least one-third of these patients were "suboptimally managed." In another retrospective analysis, statins were reported to improve 1 year survival and to reduce lower extremity embolic complications after either open or endovascular repair of AAA [22]. However, only one-half of the patients in this cohort were taking statins preoperatively, again highlighting concerns about underutilization. Chopra et al. conducted a meta-analysis of 15 randomized trials including 2292 patients, and found that perioperative statin treatment decreased risk of atrial fibrillation in patients undergoing cardiac surgery (number needed to treat, or NNT=6), as well as the risk of MI in cardiac and non-cardiac surgery $(\mathrm{NNT}=23)$, but not the risk of death [23]. Perioperative statin use reduced mean length of hospital stay. A Cochrane review [24], however, found insufficient evidence "to conclude that statin use resulted in either a reduction or an increase in any of the outcomes examined." The studies included in the Cochrane review were heterogeneous: five were statin vs placebo studies, but only 178 patients were included in the analysis. The perioperative literature is not robust, but does suggest a benefit to using preoperative statins for high-risk patients, such as those undergoing vascular surgery.

\section{Statins reduce long-term risk in vascular surgery patients}

The long-term risk reduction literature is reasonably clear: statins are strongly recommended for all patients with Atherosclerotic Cardiovascular Disease (ASCVD) in order to reduce their CV risk. The most recent ACC/AHA guidelines for blood cholesterol simplify statin regimens for high-risk patients (those with known ASCVD) to high-intensity statin (atorvastatin $80 \mathrm{mg}$ or rosuvastatin $20 \mathrm{mg}$ or equivalent) [6]. Thus, the majority of vascular surgery patients, especially those undergoing treatment of arterial vaso-occlusive disease (including infrainguinal, aortic, and carotid), should ideally be treated with high-intensity statin therapy for long-term risk reduction. A large private-insurer database review of 1357 charts demonstrated that patients with Peripheral Arterial Disease (PAD) were undertreated: $76 \%$ were receiving a statin, $85 \%$ were on aspirin, and $65 \%$ were abstinent from smoking prior to their vascular intervention [25]. Only $46 \%$ were receiving all 3 interventions prior to their surgery. At time of discharge from the hospital after receiving vascular intervention, statin use only increased to $81 \%$. Aspirin use increased from $85.3 \%$ to $91.6 \%$, and use of both together increased to $76.5 \%$. At time of discharge, $71 \%$ were receiving both aspirin and statin and were not smoking or had received tobacco cessation counseling. A retrospective study comparing patients presenting for lower limb bypass with acute limb ischemia to those with chronic limb ischemia showed that the acute group were less likely to be on aspirin (63\% vs $75 \%)$ or a statin (55\% vs $68 \%$ ) and were more likely to be currently smoking (49\% vs 39\%) [26]. The acute limb ischemia group was more likely to have had prior vascular interventions (33 vs $24 \%$ prior ipsilateral bypass, 41 vs $29 \%$ prior ipsilateral endovascular intervention). In other words, the acute limb ischemia group was more likely to have already undergone intervention for their PAD, but was still less likely to be treated with current evidence-based therapies. The long-term under-treatment of high-risk PAD patients leaves them at risk for further $\mathrm{CV}$ events. A database study of patients with claudication or critical limb ischemia [27] demonstrated that only $32 \%$ of these patients were receiving the combination of aspirin, statin, and Angiotensin-Converting Enzyme (ACE) inhibitor, and were not smoking. The group taking all four therapies had significantly 
decreased major adverse CV events, major adverse limb events, and mortality compared to those receiving fewer than four of these therapies. While smoking is more strongly associated with the pathogenesis of aneurysm formation than atherosclerosis, abdominal aortic aneurysm patients remain at high risk for CV events. A retrospective review of patients with AAA repair found improved survival in those patients treated with "lipid-modifying treatment" compared to those without [28]. Specifically, lipid therapy was associated with reduced mortality due to aneurysm complications, CV events, and all causes in this study. Current statin use has also been associated with reduced risk of AAA rupture and with reduced mortality in those patients whose AAA does rupture [29]. The recommendations for perioperative and long-term statin use are summarized in Table 1.

\section{The Importance of Smoking Cessation in Vascular Surgery Patients}

Active smoking is associated with a number of long-term adverse outcomes in vascular surgery patients, including increased rates of mortality, MI, and limb loss [30]. Patients who undergo interventions for lower-extremity PAD have higher restenosis rates of both endovascular and open procedures when they continue smoking. The 2011 American College of Cardiology Foundation/American Heart Association (ACCF/AHA) guidelines give smoking cessation efforts for PAD patients several Class I recommendations: asking about smoking status at each visit (Level A), developing a quitting plan (Level A), offering medication therapies when not contraindicated, including varenicline, bupropion, and nicotine therapy (Level A), and having each clinician advise patients with lower-extremity PAD to stop smoking and offer assistance in quitting (Level C). Patients prescribed varenicline for smoking cessation should be appropriately counseled about the FDA black box warning for depression, suicidal ideation, and suicidal behavior. A randomized controlled trial is currently underway to prospectively evaluate neuropsychiatric adverse effects from varenicline, with results expected in 2015. Current smoking, compared to past smoking ( $>1$ year of abstinence), increases risk of perioperative (30-day) mortality, MI, stroke, and adverse pulmonary outcomes (including pneumonia and respiratory failure) [31]. However, there is little evidence for reducing perioperative adverse events by preoperative smoking cessation. One small randomized controlled trial showed improved smoking cessation rates with an intervention which included brief counseling by the nurse, educational materials, and six weeks' worth of nicotine replacement therapy; however, there was no significant reduction in combined intraoperative and postoperative complications [32]. Pulmonary literature suggests an increase in respiratory complications in patients who quit smoking less than four weeks prior to surgery [33]. Smoking cessation in the preoperative period is not addressed in the 2014 ACC/AHA Guidelines [4]. While the evidence for reducing perioperative complications by smoking cessation is weak, the evidence for long-term risk reduction is strong. Some have described the time period around vascular surgery as a "teachable moment" where patients may be motivated to make change [34]. One study used a combination of retrospective chart review and patient surveys to examine the difference in quit rates in chronic limb ischemia patients who underwent either open or endovascular intervention [35]. The patients who were active smokers, then underwent open revascularization, had 8.26 times the odds of quitting or reducing cigarette consumption by $50 \%$ when compared to those who underwent endovascular intervention. The authors felt that the decreased invasiveness and length of stay with endovascular procedures ( 0.21 days versus 11.3 days), compared to open procedures, may contribute to the difference in quit rates. In other words, patients with a more invasive procedure and/or longer hospitalization may be more motivated to quit smoking and may benefit from targeted cessation interventions after their surgery. Smoking cessation efforts are effective in this population. One randomized trial in PAD patients compared an intensive intervention (which included physician advice to quit, counseling from a study counselor, individualized letters, motivational interviewing and cognitive-behavioral techniques, and education on medications and techniques for quitting) to "minimal" intervention (which mirrors much of current practice: physician advice to quit and educational materials) [36]. Verified quit rates (by saliva cotinine or exhaled carbon monoxide levels) at six months were significantly higher in the intensively-treated group: $21.3 \%$ abstinent compared to $6.8 \%$ abstinent, $p=0.023$. Not all patients who smoke are ready to quit. For those patients who are not ready to quit or unwilling to consider cessation, evidence suggests that these patients may respond poorly to direct confrontation and argument [37]. Instead, an empathetic approach and continued discussion of smoking cessation at every visit is recommended. The recommendations for perioperative and longterm smoking cessation are summarized in Table 1.

\section{Preoperative and Long-Term Antiplatelet Therapy}

Less literature is available to address the question of antiplatelet medications for PAD patients undergoing surgery. The 2011 ACCF/AHA guideline for management of patients with PAD gave a Class I, Level A recommendation for long-term antiplatelet therapy in patients with symptomatic atherosclerotic PAD to reduce risk of MI, stroke, and vascular death [30]. Aspirin in doses of 75 to $325 \mathrm{mg}$ per day is recommended, with clopidogrel $75 \mathrm{mg}$ as "a safe and effective alternative" to aspirin (both Class I, Level B). For asymptomatic patients with ankle-brachial index $(\mathrm{ABI})<0.90$, antiplatelet therapy is given a Class IIa, level C recommendation. Routine use of warfarin is not recommended for patients with PAD who lack other indications for warfarin (e.g., VTE, mechanical valve, atrial fibrillation) (Class III [no benefit], Level B). The guidelines cite a lack of evidence for or against ticagrelor and prasugrel in this population. Two recent retrospective studies suggest that preoperative aspirin may reduce $\mathrm{CV}$ complications of vascular surgery when added to other evidence-based strategies. Lau et al. compared vascular surgery patients with Lee RCRI $\geq 3$ on aspirin, beta-blocker, and statin to those on beta-blocker and statin without aspirin [38]. Patients on the regimen containing aspirin in addition to beta-blocker and statin had reduced rates of perioperative $\mathrm{MI}$ and stroke as well as 12 -month mortality. Addition of an ACE-inhibitor to the aspirin-containing regimen did not affect the outcome. Aspirin use was not associated with an increase in major bleeding in this study. Lastly, De Martino et al.'s retrospective analysis of vascular surgery patients showed that patients on antiplatelet and statin medications preoperatively had decreased 30 -day mortality and improved 5-year survival when compared to patients receiving neither [21]. The perioperative use of clopidogrel is not well-defined and carries an increased risk for bleeding; the 2007 ACC/AHA guideline recommends discontinuing clopidogrel 5-7 days prior to elective surgery [3]. 


\begin{tabular}{|c|c|c|c|c|}
\hline & Level of Evidence, Preoperative & Preoperative Timing & Level of Evidence, Long-term & $\begin{array}{l}\text { Drugs and } \\
\text { Treatments }\end{array}$ \\
\hline $\begin{array}{l}\text { Statin } \quad \text { (HMG-CoA } \\
\text { Reductase Inhibitors) }\end{array}$ & $\begin{array}{l}\text { Continue prior statin (Class I, Level B) } \\
\text { Vascular surgery with or without other } \\
\text { risk factors (Class Ila, Level B) }\end{array}$ & $\begin{array}{l}\text { Undefined (likely safe to initiate } \\
\text { in pre- or post-op period) }\end{array}$ & $\begin{array}{l}\text { High-intensity statin for patients with } \\
\text { clinical ASCVD, age } \leq 75 \text { years (Class } \\
\text { I, Level A) }\end{array}$ & $\begin{array}{l}\text { High-intensity statin: } \\
\text { Atorvastatin (40)-80 } \\
\text { mg/day } \\
\text { Rosuvastatin } \\
\text { (40) mg/day }\end{array}$ \\
\hline Antiplatelet & Not defined & $\begin{array}{l}\text { Undefined for aspirin, likely safe } \\
\text { to initiate in pre- or post-op } \\
\text { period; Clopidogrel should be } \\
\text { held 5-7 days prior to surgery }\end{array}$ & $\begin{array}{l}\text { Antiplatelet therapy for symptomatic } \\
\text { PAD (Class I, Level A) }\end{array}$ & $\begin{array}{l}\text { Aspirin } 75-325 \mathrm{mg} / \\
\text { day, Clopidogrel } 75 \\
\mathrm{mg} / \text { day }\end{array}$ \\
\hline Beta-blocker & $\begin{array}{l}\text { Continue in patients stable on beta- } \\
\text { blockers (Class I, Level C) Titrated to HR } \\
\text { and BP for vascular surgery patients at } \\
\text { high CV risk (Class Ila, Level B-C) }\end{array}$ & $\begin{array}{l}\text { Ideally } 2-4 \text { weeks prior to } \\
\text { surgery with titration of heart } \\
\text { rate and blood pressure }\end{array}$ & $\begin{array}{l}\text { For blood pressure reduction in PAD } \\
\text { patients, not contraindicated in PAD } \\
\text { (Class I, Level A) }\end{array}$ & $\begin{array}{l}\text { Many possible: } \\
\text { metoprolol tartrate } \\
\text { or } \quad \text { succinate, } \\
\text { carvedilol, nebivolol }\end{array}$ \\
\hline Smoking Cessation & $\begin{array}{l}\text { Undefined; smoking cessation }<4 \text { weeks } \\
\text { pre-op may increase risk of pulmonary } \\
\text { complications }\end{array}$ & & $\begin{array}{l}\text { Smokers \& former smokers: ask about } \\
\text { smoking at each visit, offer counseling } \\
\& \text { quit plan, and offer pharmacologic } \\
\text { therapy (Class I, Level A) PAD } \\
\text { patients who smoke: advise by every } \\
\text { clinician to quit and offer treatment } \\
\text { (Class I, Level C) }\end{array}$ & $\begin{array}{l}\text { Varenicline, } \\
\text { bupropion, nicotine } \\
\text { replacement } \\
\text { therapy; behavioral } \\
\text { therapy }\end{array}$ \\
\hline
\end{tabular}

Table 1: Recommended Strategies for Risk Reduction in Vascular Surgery Patients

\section{Conclusion}

Lower-level evidence suggests that perioperative use of statins and aspirin may reduce CV surgical complications. The long-term risk reduction evidence is clear: PAD patients warrant treatment with statins, antiplatelet therapy, and smoking cessation. Abdominal aortic aneurysm patients may also benefit from treatment with statins for both and long-term perioperative risk reduction. Despite a lack of robust randomized-control data for statin-initiation prior to surgery, the perioperative period may represent a valuable opportunity to initiate evidence-based therapy for long-term risk reduction in PAD patients. As such, a best-practice approach to these patients may include initiation of statin and aspirin medication at the preoperative visit, in addition to smoking cessation counseling (Table 1). Betablockade may be initiated at this visit if indicated for those patients at highest risk for CV events (especially in those with known coronary disease), so long as careful attention is paid to hemodynamic parameters. Just as the perioperative period may be a valuable "teachable moment" for smoking cessation, it may also be an important opportunity to initiate life-saving long-term therapy for these high risk patients. Investigations which address perioperative blood pressure and glucose management in vascular surgery patients are current very limited; these will be important targets for future research.

\section{References}

1. Lee TH, Marcantonio ER, Mangione CM, Thomas EJ, Polanczyk CA, et al. (1999) Derivation and prospective validation of a simple index for prediction of cardiac risk of major noncardiac surgery. Circulation 100: 1043-1049.

2. Eagle KA, Berger PB, Calkins H, Chaitman BR, Ewy GA, et al. (2002) ACC/AHA guideline update for perioperative cardiovascular evaluation for noncardiac surgery executive summary: a report of the American College of Cardiology/American Heart Association Task Force on Practice Guidelines (Committee to Update the 1996 Guidelines on
Perioperative Cardiovascular Evaluation for Noncardiac Surgery). J Am Coll Cardiol 39: 542-553.

3. Fleisher LA, Beckman JA, Brown KA, Calkins H, Chaikof E, et al.(2000) ACC/AHA 2007 Guidelines on Perioperative Cardiovascular Evaluation and Care for Noncardiac Surgery: Executive Summary: A Report of the American College of Cardiology/American Heart Association Task Force on Practice Guidelines (Writing Committee to Revise the 2002 Guidelines on Perioperative Cardiovascular Evaluation for Noncardiac Surgery) Developed in Collaboration With the American Society of Echocardiography, American Society of Nuclear Cardiology, Heart Rhythm Society, Society of Cardiovascular Anesthesiologists, Society for Cardiovascular Angiography and Interventions, Society for Vascular Medicine and Biology, and Society for Vascular Surgery. J Am Coll Cardiol 50: 1707-1732.

4. Fleisher LA, Fleischmann KE, Auerbach AD, Barnason SA, Beckman JA, et al. (2014) 2014 ACC/AHA Guideline on Perioperative Cardiovascular Evaluation and Management of Patients Undergoing Noncardiac Surgery: Executive Summary: A Report of the American College of Cardiology/American Heart Association Task Force on Practice Guidelines. Circulation 130.

5. Wijeysundera DN, Duncan D, Nkonde-Price C, Virani SS, Washam JB, et al. (2014) Perioperative Beta Blockade in Noncardiac Surgery: A Systematic Review for the 2014 ACC/AHA Guideline on Perioperative Cardiovascular Evaluation and Management of Patients Undergoing Noncardiac Surgery: A Report of the American College of Cardiology/ American Heart Association Task Force on Practice Guidelines. Circulation.

6. Stone NJ, Robinson J, Lichtenstein AH, Bairey Merz CN, Lloyd-Jones DM, et al. (2013) 2013 ACC/AHA Guideline on the Treatment of Blood Cholesterol to Reduce Atherosclerotic Cardiovascular Risk in Adults: A Report of the American College of Cardiology/American Heart Association Task Force on Practice Guidelines. J Am Coll Cardiol.

7. Ford MK, Beattie WS, Wijeysundera DN (2010) Systematic review: prediction of perioperative cardiac complications and mortality by the revised cardiac risk index. Ann Intern Med 152: 26-35.

8. Gupta PK, Gupta H, Sundaram A, Kaushik M, Fang X, et al. (2011) Development and validation of a risk calculator for prediction of cardiac risk after surgery. Circulation 124: 381-387. 
9. Cohen ME, Ko CY, Bilimoria KY, Zhou L, Huffman K, et al. (2013) Optimizing ACS NSQIP modeling for evaluation of surgical quality and risk: patient risk adjustment, procedure mix adjustment, shrinkage adjustment, and surgical focus. See comment in PubMed Commons below J Am Coll Surg 217: 336-346.

10. Poldermans D, Boersma E, Bax JJ, Thomson IR, van de Ven LL, et al. (1999) The effect of bisoprolol on perioperative mortality and myocardial infarction in high-risk patients undergoing vascular surgery. Dutch Echocardiographic Cardiac Risk Evaluation Applying Stress Echocardiography Study Group. N Engl J Med 341:1789-1794.

11. Dunkelgrun M, Boersma E, Schouten O, Koopman-van Gemert AW, van PF, et al. (2009) Bisoprolol and fluvastatin for the reduction of perioperative cardiac mortality and myocardial infarction in intermediate-risk patients undergoing noncardiovascular surgery: a randomized controlled trial (DECREASE-IV). Ann Surg 249: 921-926.

12. Erasmus MC Follow-up Investigation Committee (2012) Report on the 2012 follow-up investigation of possible breaches of academic integrity.

13. Devereaux PJ, Yang H, Yusuf S, Guyatt G, Leslie K, et al. (2008) Effects of extended-release metoprolol succinate in patients undergoing noncardiac surgery (POISE trial): a randomised controlled trial. Lancet 371:1839-1847.

14. Bangalore S, Messerli FH, Kostis JB, Pepine CJ (2007) Cardiovascular protection using beta-blockers: a critical review of the evidence. J Am Coll Cardiol 50: 563-572.

15. Fleischmann KE, Beckman JA, Buller CE, Calkins H, Fleisher LA, et al. (2009) 2009 ACCF/AHA focused update on perioperative beta blockade. J Am Coll Cardiol 54: 2102-2128.

16. Bhave PD, Goldman LE, Vittinghoff E, Maselli JH, Auerbach A (2012) Statin use and postoperative atrial fibrillation after major noncardiac surgery. Heart Rhythm 9:163-169.

17. de Bruin JL, Baas AF, Heymans MW, Buimer MG, Prinssen M, et al. (2014) Statin therapy is associated with improved survival after endovascular and open aneurysm repair. J Vasc Surg 59: 39-44.

18. Heyer EJ, Mergeche JL, Bruce SS, Ward JT, Stern Y, et al. (2013) Statins reduce neurologic injury in asymptomatic carotid endarterectomy patients. Stroke 44: 1150-1152.

19. Moulakakis KG, Matoussevitch V, Borgonio A, Gawenda M, Brunkwall J (2010) Evidence that statins protect renal function during endovascular repair of AAAs. Eur J Vasc Endovasc Surg 40: 608-615.

20. Iannuzzi JC, Rickles AS, Kelly KN, Rusheen AE, Dolan JG, et al. (2014) Perioperative pleiotropic statin effects in general surgery. Surgery 155: 398-407.

21. De Martino RR, Eldrup-Jorgensen J, Nolan BW, Stone DH, Adams J, et al. (2014) Perioperative management with antiplatelet and statin medication is associated with reduced mortality following vascular surgery. J Vasc Surg 59: 1615-1621.

22. Galinanes EL, Reynolds S, Dombrovskiy VY, Vogel TR (2014) The impact of preoperative statin therapy on open and endovascular abdominal aortic aneurysm repair outcomes. Vascular.

23. Chopra V, Wesorick DH, Sussman JB, Greene T, Rogers M, et al. (2012) Effect of perioperative statins on death, myocardial infarction, atrial fibrillation, and length of stay: a systematic review and meta-analysis. Arch Surg 147: 181-189.

24. Sanders RD, Nicholson A, Lewis SR, Smith AF, Alderson P (2013) Perioperative statin therapy for improving outcomes during and after noncardiac vascular surgery. Cochrane Database Syst Rev 7: CD009971.
25. Ardati AK, Kaufman SR, Aronow HD, Nypaver TJ, Bove PG, et al. (2012) The quality and impact of risk factor control in patients with stable claudication presenting for peripheral vascular interventions. Circ Cardiovasc Interv 5: 850-855.

26. Baril DT, Patel VI, Judelson DR, Goodney PP, McPhee JT, et al. (2013) Outcomes of lower extremity bypass performed for acute limb ischemia. J Vasc Surg 58: 949-956.

27. Armstrong EJ, Chen DC, Westin GG, Singh S, McCoach CE, et al.(2014) Adherence to guideline-recommended therapy is associated with decreased major adverse cardiovascular events and major adverse limb events among patients with peripheral arterial disease. J Am Heart Assoc 3: 000697.

28. Parmar GM, Lowman B, Combs BR, Taylor SM, Patterson MA, et al. (2013) Effect of lipid-modifying drug therapy on survival after abdominal aortic aneurysm repair. J Vasc Surg 58: 355-363.

29. Wemmelund H, Høgh A, Hundborg HH, Thomsen RW, Johnsen SP, et al. (2014) Statin use and rupture of abdominal aortic aneurysm. Br J Surg 101: 966-975.

30. Rooke TW, Hirsch AT, Misra S, Sidawy AN, Beckman JA, et al.(2011) 2011 ACCF/AHA focused update of the guideline for the management of patients with peripheral artery disease (updating the 2005 guideline): a report of the American College of Cardiology Foundation/American Heart Association Task Force on Practice Guidelines: developed in collaboration with the Society for Cardiovascular Angiography and Interventions, Society of Interventional Radiology, Society for Vascular Medicine, and Society for Vascular Surgery. J Vasc Surg 58: 2020-2045.

31. Musallam KM, Rosendaal FR, Zaatari G, Soweid A, Hoballah JJ, et al. (2013) Smoking and the risk of mortality and vascular and respiratory events in patients undergoing major surgery. JAMA Surg 148: 755-762.

32. Lee SM, Landry J, Jones PM, Buhrmann O, Morley-Forster P (2013) The effectiveness of a perioperative smoking cessation program: a randomized clinical trial. Anesth Analg 117: 605-613.

33. Nakagawa M, Tanaka H, Tsukuma H, Kishi Y (2001) Relationship between the duration of the preoperative smoke-free period and the incidence of postoperative pulmonary complications after pulmonary surgery. Chest 120: 705-710.

34. Warner DO (2006) Perioperative abstinence from cigarettes: physiologic and clinical consequences. Anesthesiology 104: 356-367.

35. Rajaee S, Cherkassky L, Marcaccio EJ Jr, Carney WI Jr, Chong TT, et al. (2014) Open revascularization procedures are more likely to influence smoking reduction than percutaneous procedures. Ann Vasc Surg 28: 990-998.

36. Hennrikus D, Joseph AM, Lando HA, Duval S, Ukestad L, et al. (2010) Effectiveness of a smoking cessation program for peripheral artery disease patients: a randomized controlled trial. J Am Coll Cardiol 56: 2105-2112.

37. Black JH 3rd (2010) Evidence base and strategies for successful smoking cessation. J Vasc Surg 51: 1529-1537.

38. Lau WC, Froehlich JB, Jewell ES, Montgomery DG, Eng KM, et al. (2013) Impact of adding aspirin to beta-blocker and statin in high-risk patients undergoing major vascular surgery. Ann Vasc Surg 27: 537-545. 